International Journal of Instruction e-ISSN: 1308-1470 • www.e-iji.net

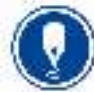

Article submission code: 20200402072256
Received: 02/04/2020

Revision: 18/10/2020
April 2021 • Vol.14, No.2

p-ISSN: 1694-609X

pp. 757-772

Accepted: 10/11/2020

OnlineFirst: 26/02/2021

\title{
A Comparison of Achievement in Large University Classes Using Mentored Groups versus Lectures
}

\section{Kanyuma Jitjumnong}

Ph.D. candidate, King Mongkut's University of Technology Thonburi, Thailand, kanyuma.j@mail.kmutt.ac.th

\section{Surachai Suksakulchai}

Assoc. Prof., King Mongkut's University of Technology Thonburi, Thailand, surachai.suk@mail.kmutt.ac.th

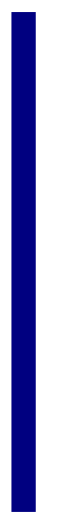

The purpose of this study was to determine if there were achievement gains in large classes with lectures alone versus with lectures and mentored groups. To measure achievement, mid-term to final-grade gains were compared between two sections ( $\mathrm{n}=82$ and $\mathrm{n}=99$ ) of a undergraduate course in Digital Circuit Design that had lectures alone versus three sections $(n=131, n=104, n=115)$ of the course that had lectures as well as mentored groups. In addition, the study surveyed students in one section in order to identify students' $(\mathrm{n}=115)$ satisfaction with the groups and mentors' $(\mathrm{n}=19)$ satisfaction with mentoring. Quantitative analysis using SPSS involved t-tests to identify significant differences. Results revealed statistically significant higher achievement for the three classes with lectures plus mentored groups versus the classes with lecture alone. Regarding satisfaction, $85 \%$ of students reported that they learned better in mentored groups. All mentors reported learning more as a mentor.

Keywords: mentoring, mentored groups, large university classes, achievement, satisfaction, higher education, lectures

\section{INTRODUCTION}

The global demand for higher education (HE) is resulting in more frequent reliance on large class sizes particularly in undergraduate courses (Iipinge, 2018). Some of these reach sizes of 300 to 1000 (Mulryan-Kyne, 2010) and are common in many universities (Kumaraswamy, 2019; Stanley \& Porter, 2002). The reliance on large classes can be attributed to the massification of HE (Hornsby \& Osman, 2014). As Evans et al. (2020) explained in relation to massification, universities that once enrolled 4-5\% of secondaryschool graduates are now enrolling between 30 and 50\% of those graduates. Those students are also are more culturally, socially and ethnically diverse as opposed to elite (Evans et al., 2020) Massification has occurred at the same time as universities are being

Citation: Jitjumnong, K., \& Suksakulchai, S. (2021). A Comparison of Achievement in Large University Classes Using Mentored Groups versus Lectures. International Journal of Instruction, 14(2), 757-772. https://doi.org/10.29333/iji.2021.14242a 
pressured to reduce spending. Not surprisingly, reliance on large classes presents an opportunity to save on costs (e.g., instructor salaries) (Álvarez et al., 2017).

This increased reliance on large classes may offer financial savings, but it comes with problems for learners (Álvarez et al., 2017) and for both experienced and inexperienced instructors (Lantz, Smith \& Branney, 2008). These problems may also be compounded given the increased diversity of the students. Those with fewer resources on which to draw are likely to be less engaged and more inclined to drop out (Cornelius, Wood, \& Lai, 2016). Lower-achieving students may be reluctant to participate, interact less, and, as a result, achieve less (Kumaraswamy, 2019). Large classes can result in higher failure rates for first-year students (Twigg, 2003), inconsistent learning experiences, lack of interaction, decreased motivation, less participation and lower achievement (Cheng et al., 2019). In general, Dillon, Kokkelenberg, and Christy (2002) made 760,000 observations over a four-year period and identified a decrease in students' grades when class size increased. Kokkelenberg, Dillon, and Christy (2008) found that large classes negatively affected grades even when their model controlled for effects such as ability, course level and gender. Large classes also present challenges for instructors. These challenges can arise because having more students means, as Cheng et al. (2019) observed, an increase in workload. Workload issues can force instructors into a reliance on lectures as the dominant approach to learning (Onwu \& Stoffels, 2005). Lectures can lead to class management difficulties and less attention to weak students (Kumaraswamy, 2019).

\section{Purpose}

In spite of the problems that result from large classes, their existence presents "promise and opportunities for innovation in support of student learning" (Hornsby \& Osman, 2014, p. 711). In this regard, large classes represent contexts within which to experiment with new and innovative approaches that take advantage of class size to improve learning and achievement. This paper reports on one such case in which an instructor investigated use of mentored groups in conjunction with lectures in order to improve student achievement in large classes. In general, higher education has not kept pace with building understanding of formal mentoring (Cornelius, Wood, \& Lai, 2016; Gershenfeld, 2014). Furthermore, formal mentoring programmes may vary considerably in terms of design (Ragins et al., 2000) yet research is limited on features of such design (Christie, 2014). The review of the literature conducted for this study did not uncover any studies of using mentored groups to improve achievement in large university classes.

The purpose of this study was to determine if there were achievement gains in large undergraduate university classes learning with lectures alone versus with lectures and mentored groups. To measure achievement, mid-term to final-grade gains were compared between two sections ( $\mathrm{n}=82$ and $\mathrm{n}=99$ ) of a course in Digital Circuit Design that had lectures alone versus three sections $(n=131, n=104, n=115)$ of the course that had lectures as well as mentored groups. The course was part of an electronic engineering program at a large technical university in Bangkok, Thailand. In addition, 
the study surveyed students in one section in order to identify students' $(n=115)$ satisfaction with the group and mentors' $(n=19)$ satisfaction with mentoring.

\section{LITERATURE REVIEW}

\section{Groups}

Reliance on groups in large classes supports a shift from teacher- to student-centered learning, promotes interaction, helps students evaluate their learning and makes studentto-student cooperation easier (Kumaraswamy, 2019). Group work can promote better understanding (Sansivero, 2016) and help with problem-solving, sharing of knowledge and of expertise (Ferdous \& Karim, 2019). In general, there is a long tradition of and literature devoted to group work. It is sometimes referred to as cooperative learning (e.g., see Kirstein \& Kunz, 2015) or team-based learning (Michaelsen \& Sweet, 2011). Team-based learning is more than simply putting students together in groups. Michaelsen and Sweet (2011) explained that team-based learning should involve strategically-formed, permanent groups. Their argument is supported by Kirstein and Kunz (2015) who found that, if students are left to independently form their own groups, they tend to do so with their friends.

Scager et al. (2018) referred to cooperative and team-based learning as a form of collaborative learning. However, these terms go beyond the conceptions of group work and emphasize the value of adopting specific approaches. Collaborative learning, explained Scager et al. (2018), is not simply putting students in groups, rather such learning must emphasize interactivity and not merely dividing the work among individual members in a "stapler approach." Collaborative learning must involve a process whereby members explain, discuss, share and communicate with each other (Scager et al., 2018) and involves positive interdependence (Johnson et al., 2014). With regards to cooperative learning, the emphasis is not on simply learning in groups but on goal-oriented work (Petty, 2006). In addition to being goal-oriented, the point of such work, as Kirstein and Kunz (2015) explained, is so that learners can support each other by learning from each other and by sharing opposing views. Such learning can actually promote higher-order thinking (Cunningham, 2008).

\section{Mentored Groups}

In terms of strategically forming groups, Scager et al. (2016) found regarding the group composition that mixed-ability groups increased performance for lower-ability students. Kozhevnikov et al. (2014) found that heterogeneity of groups promoted greater creativity within groups. One approach to ensuring that the heterogeneous, strategicallyformed groups remain interactive and goal-oriented is to rely on mentors. In general, mentoring programmes create supportive learning environments (Pinilla et al., 2015) and positively affect students' transition to university as well as their retention (Fox et al., 2010). This support during the transition to university may be important when students are experiencing stress (Coffman \& Gillian, 2002). Reliance on mentors can also promote student engagement and participation (Christie, 2014), increased class attendance, improved grades (Rhodes, Grossman, \& Resch, 2000; Thompson \& KellyVance, 2001) and motivation (Won \& Choi, 2017). When students are mentored well, 
they tend to be more focused on and more motivated to achieve their academic goals (Gandara \& Mejorado, 2005). Won and Choi (2017) explained that mentors can offer, not only knowledge but also psychological and social support. Not surprisingly, therefore, mentoring can be explained in terms of social learning theory (Bandura, 1977) whereby the cognitive process of learning occurs socially as individuals observe and imitate and the mentee is positively socialised (Strayhorn \& Terrell, 2007). The relationship between the mentor and mentee strengthens the mentees' sense of self (Palmer et al., 2015) through the provision of emotional support as well as friendship (Cornelius, Wood, \& Lai, 2016).

Mentoring is typically conceived as a relationship between a more and less experienced person and involves support such as guidance, encouragement, help with challenging tasks, or simply, more passively, through role modelling behaviours needed for success (Hernandez et al., 2017). For example, Hawkins and Fontenot (2010) described mentoring as a relationship between two people. Likewise, Palmer et al. (2015) referred to mentoring as a relationship between two people whereby one mentor models skills and behaviours to a mentee. However, Huizing (2012) explained that although mentoring is typically thought of as "a dyadic relationship," group mentoring implies a "polyad mentoring relationship of more than two people" (p. 28). In the case of one mentor to many mentees, Huizing (2012) described this approach as one in which a mentor serves as a guide, catalyst, and advisor to members of the group. Skaniakos and Piirainen (2019) referred to this approach as peer-group mentoring or tutoring. It may also be referred to as mentoring circles (Darwin \& Palmer, 2009). There have been studies of teachers as mentors, for example in online environments. In this regard, Mrstik, Vasquez, and Pearl (2018) reported on a study involving special-education teachers mentoring novice teachers by providing professional development through use of short video clips. Results showed that mentored teachers were able to increase and improve their use of visual supports as a result of having been mentored. There have also been reports of cases in which senior faculty mentor younger faculty in large classes (Idachaba, 2018). This study, in contrast, focuses on mentoring among students as opposed to faculty.

The review of the literature conducted for this study did not identify any investigations of the impact of group mentoring on achievement in large classes at the post-secondary level. Studies more commonly focus on one-to-one mentoring. In addition, they are more likely to be conducted at the elementary or secondary levels. In addition, the studies may focus on various outcomes but not specifically on achievement. For example, Kuperminc et al. (2020) studied resilience in contexts of group mentoring "among academically vulnerable adolescents." Stoeger et al. (2017) studied online group mentoring with secondary-school girls enrolled in STEM programs. They found that the mentoring resulted in more STEM communication, more discussion of STEM career options, more STEM-related networking and elective intentions. Neither of these studies focused on achievement or on the post-secondary level. 


\section{METHOD}

\section{Context and Data Collection}

This study relied on a quantitative, non-experimental, causal-comparative research design. In causal-comparative research, comparisons are made between two or more different groups (Salkind, 2010). Causal-comparative research involves ex post facto designs (Gall et al., 2007) with the independent variable (e.g., type of instruction) having already occurred. The causal-comparative design was chosen for the study because it allowed the researchers to study data that were already available in the form of students' gains in grades from the mid-term to final exam. The research involved five different sections of the same course. Two of the sections involved instruction by lecture alone. Three of the sections also received instruction in the form of lecture. However, they also received instruction in the form of mentored groups in addition to the lecture. Achievement was measured using comparisons of mid-term and final grades. Quantitative analysis involved t-tests to identify significant differences between grades.

In addition, for one section $(n=115)$, a survey was used to identify satisfaction of students $(n=115)$ as well as mentors $(n=19)$ in this section.

\section{Sample}

The study relied on convenience sampling which is a "nonprobability sampling strategy where participants are selected based on their accessibility and/or proximity to the research" (see Bornstein et al., 2013). Participants were students enrolled in five different sections $(n=82),(n=99),(n=131),(n=104),(n=115)$ of the same course over a five-year period. The course in Digital Circuit Design is part of an electronic engineering program at a large technical university in Bangkok, Thailand. It is delivered in one, three-hour session, once per week. Their instructor was the Principal Investigator (PI) with a master's degree in electronic engineering and who had previously taught the course twice per year over a period of seven years. In each section of the course, evaluation was based on a mid-term and final exam each worth $30 \%$ as well as individual assignments and a project worth $40 \%$.

\section{Procedures}

In two sections $(n=82),(n=99)$, instruction involved a traditional lecture with mid-term and final examinations. In three other sections $(n=131),(n=104),(n=115)$, for the first seven weeks, there was a similar lecture. After the mid-term examination, however, the instructor organized the class into groups of mixed ability based on their midterm examination results. The instructor assigned a mentor to each group. For the next seven weeks, the instructional approach involved lecture along with mentored groups.

\section{Procedures for Grouping}

The instructor assigned students to their groups based on mid-term grades. Grouping meant that, during class, students in the same groups sat together (see figure 1). Students could choose to sit where they wanted within their group, but mentors were assigned to a 
central position within the group. Each group was equally represented and mixed in terms of grades with higher, medium and lower-achieving students. The size of groups depended on the number of students. For example, in the class of 131, there were 14 groups of nine with one group of five. In the large university class $(n=115)$, there were eighteen groups of six and one group of seven with one mentor per group. Figure 1 shows a sample seating arrangement for a large $(\mathrm{n}=131)$ class.

\section{Instructor}
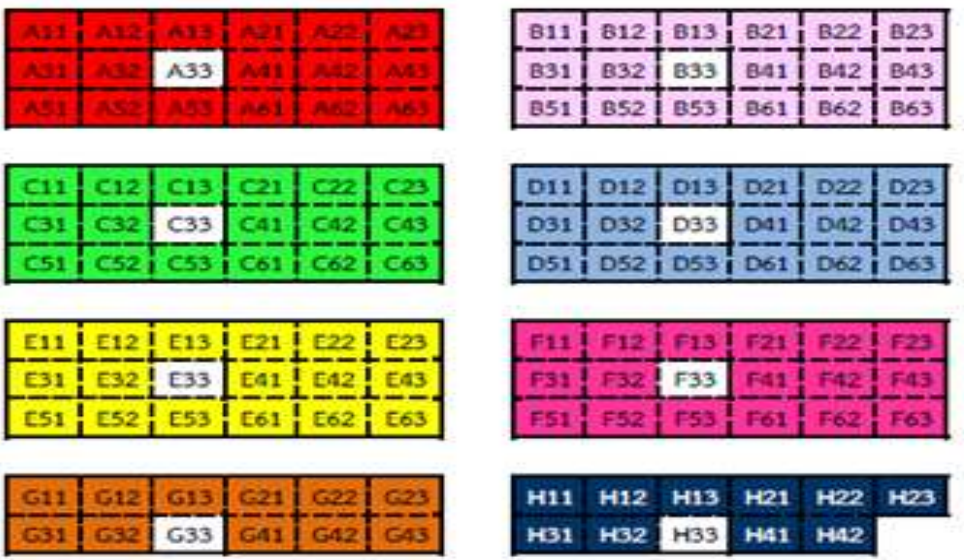

Figure 1

Seating arrangement for a large class: Group mentor sits at position 33.

\section{Selection Procedures for Mentors}

The potential mentors were first identified by the instructor on the basis of their midterm grades and by informal instructor observation during the first seven weeks of the course. However, grades were not the only criteria for selection. The instructor took into account Terrion's (2010) proposals for the selection of mentors that the process should also consider personal characteristics such as empathy and availability. Next, in each class, the instructor invited these potential mentors to participate in a meeting in which she outlined the role of the mentors. Mentors were informed that their role would be voluntary and that they could choose to not participate. During this meeting, students could ask questions about their role and discuss the implications for their workload, issues about interpersonal interactions and about specific strategies to help other students. The instructor also discussed ethical issues such as non-disclosure of personal information about students in their groups. Finally, the guidelines proposed how to help students without doing the work for them. Mentors' roles included the following:

- Model skills and behaviours needed for success.

- Offer guidance, and encouragement.

- $\quad$ Provide support and help with challenging topics. 
- Promote student engagement and participation.

- Encourage attendance.

- Stimulate motivation.

- Encourage students to be focused.

All invited students agreed to participate as mentors. Following each class, the instructor met with the mentors to discuss any problems, answer their questions and propose strategies. The mentors could also provide feedback to the instructor about their group's progress.

In relation to procedures for the survey of students' $(n=115)$ and mentors' $(n=19)$ satisfaction, the survey was completed at the end of the course without the instructor present. Students required approximately five to ten minutes to complete it.

\section{Instruments}

Data collection related to students' grades relied on an instructor-created, three-hour, mid-term and three-hour final examination. Regarding the satisfaction survey, it was instructor-created. For the students' $(n=115)$ survey, there were eight questions pertaining to groups and two pertaining to the mentoring experience. For the mentors $(n=19)$, there were three questions. The satisfaction survey invited students to rate their satisfaction by indicating a degree of frequency for each item on a five-point Likertscale. The Cronbach $\alpha$ value of the survey was 0.819 , representing high confidence.

\section{Data Analysis}

Analysis relied on descriptive statistics using SPSS and on t-tests to measure significance. Prior to analysis, the normality of the data was tested using KolmogorovSmirnov with Lillefors correction. The data the data were proven to be normally distributed.

\section{FINDINGS}

Table 1 shows that there was no significant improvement in students' achievement as measured by gains in grades from the mid-term to the final examination. Given a mean grade of 9 or $10 \%$ out of $30 \%$, it is evident that achievement was generally very low. 
Table 1

Comparison of students' mid-term and final exam scores

\begin{tabular}{llllll}
\hline Lecture & $\mathrm{n}$ & $\begin{array}{l}\text { Mean } \\
130 \%\end{array}$ & SD. & t-test & Sig. \\
\hline Midterm & 82 & $9 \%$ & 4.68 & 1.491 & .140 \\
Final & 82 & $10 \%$ & 5.78 & & \\
\hline Midterm & 99 & $10 \%$ & 5.67 & 0.379 & .706 \\
Final & 99 & $10 \%$ & 4.00 & & \\
\hline
\end{tabular}

$* \mathrm{p}<0.05$

Table 2 shows the results of t-tests to identify if there was a significant improvement in students' achievement after treatment using lectures + mentored groups versus treatment with lecture only. Results are presented for three different classes. In all three classes, results showed that treatment by lecture + mentored groups resulted in significantly higher grades than learning by lecture alone.

Table 2

Comparison of student's mid-term and final exam scores

\begin{tabular}{|c|c|c|c|c|c|}
\hline Approach & $\mathrm{n}$ & $\begin{array}{l}\text { Mean } \\
130 \%\end{array}$ & SD. & t-test & Sig. \\
\hline $\begin{array}{l}\text { Lecture } \\
\text { (Midterm) }\end{array}$ & 131 & $12 \%$ & 6.37 & \multirow{2}{*}{8.014} & \multirow{2}{*}{$.000 * *$} \\
\hline Lecture + mentored groups (Final) & 131 & $16 \%$ & 5.91 & & \\
\hline $\begin{array}{l}\text { Lecture } \\
\text { (Midterm) }\end{array}$ & 104 & $14 \%$ & 5.50 & \multirow{2}{*}{5.917} & \multirow{2}{*}{$.000 * *$} \\
\hline Lecture + mentored groups (Final) & 104 & $17 \%$ & 5.54 & & \\
\hline $\begin{array}{l}\text { Lecture } \\
\text { (Midterm) }\end{array}$ & 115 & $10 \%$ & 7.32 & \multirow[t]{2}{*}{15.024} & \multirow[t]{2}{*}{$.000 * *$} \\
\hline Lecture + mentored groups (Final) & 115 & $19 \%$ & 5.34 & & \\
\hline
\end{tabular}

**p $<0.01$

Figure 2 presents the results of students' satisfaction $(n=115)$ with groups (eight questions) and with mentors (two questions). Results showed that $85 \%$ of students found that groups worked well for them and they liked to be in a group. However, only $66 \%$ reported that groups reduced distractions. Eighty-five percent reported that they learned better with a mentor. However, a smaller percentage (72\%) reported that they felt they could ask the mentor for help. 


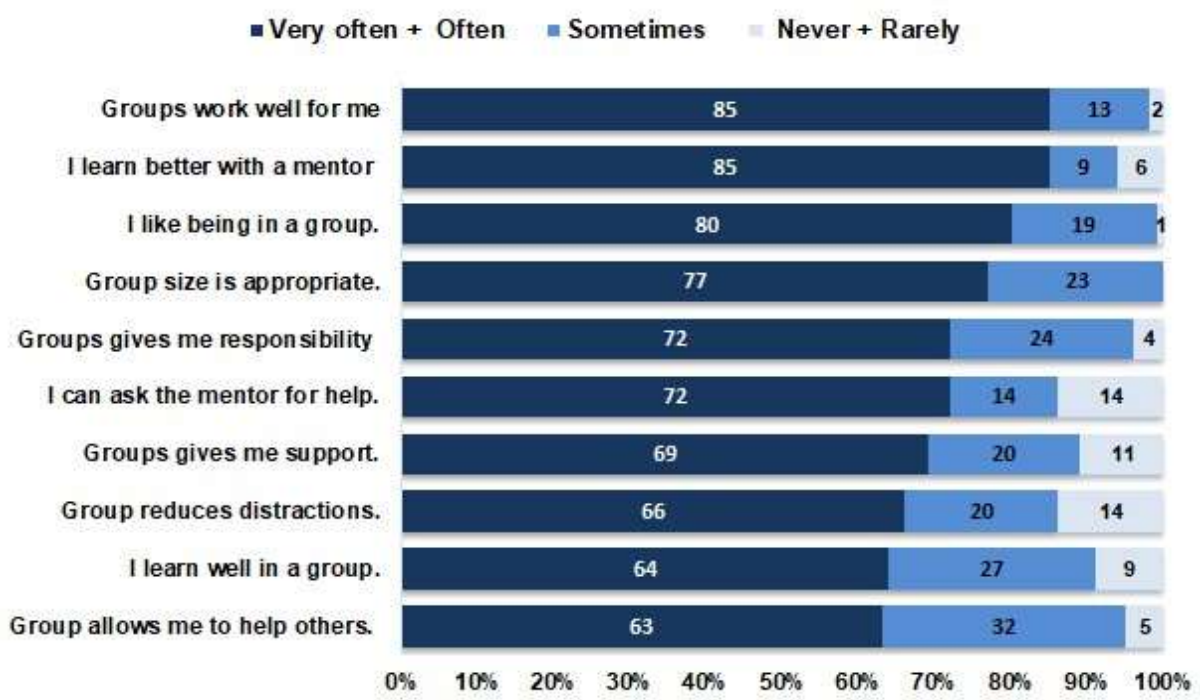

Figure 2

Results of students' satisfaction $(\mathrm{n}=115)$ with groups and mentors

Figure 3 presents the results of the satisfaction survey by the 19 mentors in the class of 115. All mentors reported learning more as a mentor and regularly engaging in mentoring. However, $25 \%$ reported that classmates were only sometimes interested in being mentored.

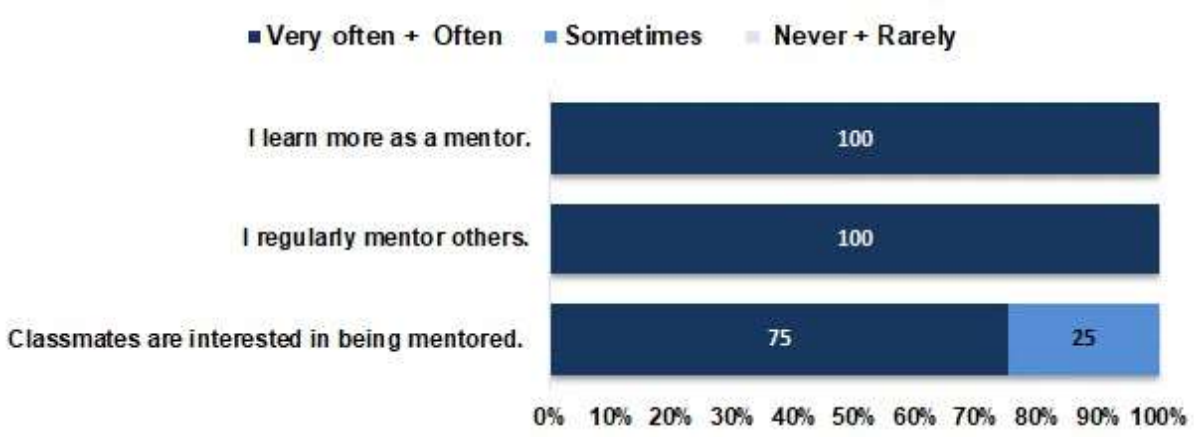

Figure 3

Results of mentors' satisfaction ( $\mathrm{n}=19)$

\section{DISCUSSION}

The massification of HE is resulting in an increased reliance on large classes and in negative outcomes for students and instructors. However, the challenges of large classes also provide an opportunity to innovate with alternative and innovative approaches to learning. This study investigated one such opportunity. The study combined mentored 
groups with lectures in large classes to improve student outcomes in terms of achievement. Five classes were compared in terms of approach and achievement. Two classes involved lectures alone while the three other classes involved lectures along with mentored groups.

Results revealed that with the lecture alone, students' grades did not significantly improve from the mid-term to the final. The final mean was actually a failure $(10 / 30 \%)$ for both sections $(n=82)$ and $(n=99)$. This high failure rate has been reported in other contexts and has been linked to difficulties that students experience with mathematics and calculus which are typically required in undergraduate engineering. A study of freshmen engineering students in Brazil reported that failure rates of more than 50\% were not uncommon in schools of engineering (see Zarpelon, Resende, \& Reis, 2015). Mzoughi (2000) reported failure rates of $40 \%$ of students in pre-engineering physics.

Those types of failures under these conditions provide a rationale for the need to investigate other approaches to learning in large classes. In this regard, three sections of the course were taught using lectures alone up to the midterm. However, after the midterm exam, the instructor incorporated use of mentored groups along with the lectures. Results revealed that there was a significant improvement in grades from the midterm to the final. These results may be explained by Lloyd-Strovas' (2015) observations that small groups promote student involvement in their learning and offer "a safe place" for peers to share ideas, teach each other, and identify misconceptions. According to this approach, students were grouped in such a way that there was a mix of ability (as measured by mid-term exams) and each was assigned a mentor who had high ability and who was judged by the instructor to be capable of playing this role and supporting students.

The results may also be explained by De Matos-Ala and Hornsby's (2015) findings that "small group session(s)" are important in large classes in terms of supporting interaction and engagement. The effect of the mentored groups on achievement may also be explained by Ramkumar and Year's (2019) observation that small groups of peers actually simulate smaller classrooms. Similarly, Kumaraswamy (2019) used group activities in large classes to promote participation and achievement in terms of increased scores. Kumaraswamy also found an increase in students' interest. It was beyond the scope of this study to measure interaction, interest, participation, or engagement but this is something that could be explored in future studies given that these factors have been associated with higher grades. However, the study did focus on students' $(n=115)$ and mentors' $(n=19)$ levels of satisfaction regarding mentored groups in a large university class. The mentors reported high satisfaction except in relation to the item pertaining to their perceptions of how classmates responded to being mentored. Only $75 \%$ of mentors reported that their classmates were interested in being mentored. It was beyond the scope of the study to conduct follow-up interviews with mentors. However, their experiences are important. Heirdsfield, Walker, Walsh, and Wilss (2008) conducted a study of mentors' experiences in a context of peer mentoring for first-year, pre-service teachers. The authors concluded that knowing mentors' experiences is important in order to inform their training. They also proposed that mentors need to reflect on why 
they want to be mentors and be ready to accept the responsibilities and related uncertainties of this role. Overall, the authors reported that the mentors had a "powerful learning experience."

Results of students' $(n=115)$ experiences with groups suggest that it would be worthwhile to probe further through observation or interviews to find out why some students did not respond with positive satisfaction to being in a group. For example, only $64 \%$ responded that they 'very often' or 'often' learned well in a group. Only $69 \%$ reported 'very often' or 'often' regarding the frequency of support within the group. Only $66 \%$ reported that the groups reduced distractions 'very often' or 'often'. Challenges with groups have been reported in other contexts. Some of these include unequal participation (Freeman \& Greenacre, 2010), lack of students' collaborative skills (Li \& Campbell, 2008), and free-riding whereby students depend on others in the group to do the required tasks (Popov et al., 2012).

\section{CONCLUSIONS}

Problems associated with large, undergraduate university classes are many and varied and affect instructors as well as students. Low achievement is one of these problems. The purpose of this study, therefore, was to identify if adding mentored groups to lectures could improve achievement in terms of higher final grades in large university classrooms. To achieve this purpose, the researchers compared differences between mid-term and final grades within large classes with lecture alone versus large classes using mentored groups in addition to lectures. Results revealed statistically significant higher grades for the three classes with lectures and mentored groups versus the classes with lecture alone. The study also investigated students' satisfaction with groups and mentors for one class. Regarding satisfaction, $85 \%$ of students reported that they learned better in mentored groups. All mentors reported learning more as a mentor and regularly engaging in mentoring.

It was beyond the scope of this study to focus in detail on the mentors and their experiences. Huizing (2012) noted that there is a gap in the research regarding the benefits and challenges related to group mentoring. This study was limited to reliance on group mentoring in a face-to-face context. Given the growth of online learning and use of Information and Communication Technologies (ICTs) in learning, group mentoring empowered by ICTs may become a viable approach to supporting instruction in large classes. Huizing (2012) argued that "the possibilities for online group mentoring have escalated exponentially but the research quantifying these opportunities has not yet emerged" (p. 52). Darwin and Palmer (2009) conducted a study of one-to-many research mentoring among university faculty. One of their findings related to incompatibility of members in the mentored group. The present study did not assess these types of issues. However, the satisfaction survey provided preliminary results that could be further investigated in future studies.

Results of this study have shown that mentored groups can improve achievement in large classes. There has been much research on groups and much on mentors but far less on mentored groups. This study has provided some preliminary insights that can be 
further investigated in other contexts. In terms of practice, the intervention that took place in this study can be trialed by instructors in other contexts. As in this study, the researchers recommend mixed-ability groups and mentors with good academic as well as social skills. However, other mentor characteristics might be considered.

\section{REFERENCES}

Álvarez C., Baloian N., Zurita G., Guarini F. (2017) Promoting active learning in large classrooms: Going beyond the clicker. In, Gutwin C., Ochoa S., Vassileva J., Inoue T. (eds), Collaboration and Technology. CRIWG 2017. Lecture notes in computer science, vol 10391. Springer, Cham.

Bandura, A. (1977). Social learning theory. Englewood Cliffs, NJ: Prentice-Hall.

Bornstein, M., Jager, J. \& Putnick, D. (2013) 'Sampling in developmental science: situations, shortcomings, solutions, and standards', Developmental Review, 33, 357370, doi:10.1016/j.dr.2013.08.003.

Cheng, Z., Watson, S. L., Watson, W. R., \& Janakiraman, S. (2019). Attitudinal learning in large-enrollment classrooms: A case study. Tech Trends, 64(1), 158-171.

Christie, H. (2014). Peer mentoring in higher education: Issues of power and control. Teaching in Higher Education, 19(8), 955-965.

Coffman, D. L., \& Gillian, T. D., (2002). Social support, stress, and self-efficacy: Effect on students' satisfaction. Journal of College Student Retention: Research, Theory \& Practice, 4(1), 53-66.

Cornelius, V., Wood, L., \& Lai, J. (2016). Implementation and evaluation of a formal academic-peer-mentoring programme in higher education. Active Learning in Higher Education, 17(3), 193-205.

Cunningham, B. M. (2008). Using action research to improve learning and the classroom learning environment. Issues in Accounting Education, 23(1), 1-30.

Darwin, A., \& Palmer, E. (2009). Mentoring circles in higher education. Higher Education Research \& Development, 28(2), 125-136.

De Matos-Ala, J., \& Hornsby, D. J. (2015). Introducing international studies: Student engagement in large classes. International Studies Perspectives, 16(2), 156-172.

Dillon, M., Kokkelenberg, E., \& Christy, S. (2002). The effects of class size on student achievement in higher education: Applying an earnings function [Report]. New York: Cornell University. (ERIC Document Reproduction Service No. ED482389.)

Ehrenberg, R. G., Brewer, D. J., Gamoran, A., \& Willms, J. D. (2001). Class size and student achievement. Psychological Science in The Public Interest, 2(1), 1-30.

Evans, C., Rees, G., Taylor, C., \& Fox, S. (2020). A liberal higher education for all? The massification of higher education and its implications for graduates' participation in civil society. Higher Education. doi:10.1007/s10734-020-00554-x. 
Ferdous, T., \& Karim, A. (2019). Working in groups outside the classroom: Affective challenges and probable solutions. International Journal of Instruction, 12(3), 341-358.

Fox, A., Stevenson, L., Connelly, P., Duff, A., \& Dunlop, A. (2010). Peer-mentoring undergraduate accounting students: The influence on approaches to learning and academic performance. Active Learning in Higher Education, 11(2), 145-156.

Freeman, L., \& Greenacre, L. (2010). An examination of socially destructive behaviors in group work. Journal of Marketing Education, 33, 5-17.

Gall, M., Gall, J., \& Borg, W. (2007). Educational research: An introduction (8th ed.). New York: Longman.

Gandara, P. \& Mejorado, M. (2005). Putting your money where your mouth is: mentoring as a strategy to increase access to higher education. In Tierney, W., Corwin, Z. and Colyar, J., Eds., Preparing for college: Nine elements of effective outreach, SUNY Press, Albany, 89-110.

Gershenfeld, S. (2014). A review of undergraduate mentoring programs. Review of Educational Research, 84(3), 365-91.

Hawkins, J. W., \& Fontenot, H. (2010). Mentorship: The heart and soul of health care leadership. Journal of Healthcare Leadership, 2, 31-34.

Hernandez, P. R., Bloodhart, B., Barnes, R. T., Adams, A. S., Clinton, S. M., Pollack, I., .. \& Fischer, E. V. (2017). Promoting professional identity, motivation, and persistence: Benefits of an informal mentoring program for female undergraduate students. PloS One, 12(11), 1-16. doi:10.1371/journal.pone.0187531.

Heirdsfield, A., Walker, S., Walsh, K. \& Wilss, L. (2008). Peer mentoring for first year teacher education students: The mentors' experience. Mentoring \& Tutoring: Partnership in Learning, 16(2),109-124.

Hornsby, D. J., \& Osman, R. (2014). Massification in higher education: Large classes and student learning. Higher Education, 67(6), 711-719.

Huizing, R. L. (2012). Mentoring together: A literature review of group mentoring. Mentoring \& Tutoring: Partnership in Learning, 20(1), 27-55.

Idachaba, F. E. (2018). Development of a rapid mentoring scheme for managing large classes in engineering departments. Proceedings of INTED2018 Conference, 57252731. doi:10.21125/inted.2018.1363.

Iipinge, S. M. (2018). Challenges of large class teaching at the university: Implications for continuous staff development activities. The Namibia CPD Journal for Educators, 1(1),105-120. doi:10.32642/ncpdje.vi.1263.

Johnson, D. W., Johnson, R. T., \& Smith, K. A. (2014). Cooperative learning: Improving university instruction by basing practice on validated theory. Journal on Excellence in University Teaching, 25(4), 1-26. 
Kirstein, M., \& Kunz, R. (2015). Student-centred approach to teaching large classes: Friend or foe?. Meditari Accountancy Research, 23(2), 222-246. doi.10.1108/MEDAR06-2013-0025.

Kokkelenberg, E., Dillon, M. \& Christy, S. (2008). The effects of class size on student grades at a public university. Economics of Education Review, 27(2). 221-233.

Kozhevnikov, M., Evans, C., \& Kosslyn, S. M. (2014). Cognitive style as environmentally sensitive individual differences in cognition: A modern synthesis and applications in education, business, and management. Psychological Science in the Public Interest, 15(1), 3-33.

Kumaraswamy, S. (2019). Promotion of students' participation and academic achievement in large classes: An action research report. International Journal of Instruction, 12(2), 369-382.

Kuperminc, G. P., Chan, W. Y., Hale, K. E., Joseph, H. L., \& Delbasso, C. A. (2020).

The role of school-based group mentoring in promoting resilience among vulnerable high school students. American Journal of Community Psychology, doi:10.1002/ajcp.12347

Lantz, C., Smith, D., \& Branney, P. (2008). Psychology postgraduates' perspectives on teaching-related support and training. Psychology Learning \& Teaching, 7(1), 37-45.

Li, M., \& Campbell, J. (2008). Asian students' perceptions of group work and group assignments in a New Zealand tertiary institution. Intercultural Education, 19(3), 203216.

Lloyd-Strovas, J. (2015). Tips for teaching large classes. Teaching, Learning, and Professional Development Center, Texas Tech University.

Mzoughi, T. (2000). PERC-a collaboration between engineering and arts and science faculty to help insure better student preparation. In Frontiers in Education Conference, 2000. FIE 2000. 30th Annual (Vol. 1, pp. F2B-1). IEEE.

Michaelsen, L. K., \& Sweet, M. (2011). Team-based learning. New Directions for Teaching and Learning, 2011(128), 41-51.

Mrstik, S. L., Vasquez, E., \& Pearl, C. (2018). The effects of mentor instruction on teaching visual supports to novice, special education teachers. International Journal of Instruction, 11(1), 411-424.

Mulryan-Kyne, C. (2010). Teaching large classes at college and university level: Challenges and opportunities. Teaching in Higher Education, 15(2), 175-185.

Onwu, G., \& Stoffels, N. (2005). Instructional functions in large, under-resourced science classes: Perspectives of South African teachers. Perspectives in Education, 23(1), 79-91. 
Palmer, R. J., Hunt, A. N., Neal, M., \& Wuetherick, B. (2015). Mentoring, undergraduate research, and identity development: A conceptual review and research agenda. Mentoring \& Tutoring: Partnership in Learning, 23(5), 411-426.

Petty, G. (2006). Evidence based teaching. Gloucestershire, U.K.: Nelson-Thornes.

Pinilla, S., Nicolai, L., Gradel, M., Pander, T., Fischer, M. R., von der Borch, P., \& Dimitriadis, K. (2015). Undergraduate medical students using Facebook as a peermentoring platform: A mixed-methods study. JMIR Medical Education, 1(2), e12.

Popov, V., Brinkman, D., Biemans, H. J. A., Mulder, M., Kuznetsov, A., \& Noroozi, O. (2012). Multicultural student group work in higher education. International Journal of Intercultural Relations, 36(2), 302-317. doi:10.1016/j.ijintrel.2011.09.004.

Ramkumar, S., \& Year, B. (2019). Perceptions and effects of large classes in higher education in India. strength for today and bright hope for tomorrow,19(10).

Ragins, B. R., Cotton, J. L., \& Miller, J. S. (2000). Marginal mentoring: The effects of type of mentor, quality of relationship, and program design on work and career attitudes. Academy of Management Journal, 43(6), 1177-1194.

Rhodes, J. E., Grossman, J. B., \& Resch, N. L. (2000). Agents of change: Pathways through which mentoring relationships influence adolescents' academic adjustment. Child Development, 71(6), 1662-1671. doi:10.1111/1467-8624.00256.

Salkind, N. J. (2010). Encyclopedia of research design. Thousand Oaks, CA: Sage.

Sansivero, G. (2016). Challenges and advantages of collaborative learning: Developing workforce readiness in students. SEEN Magazines US Articles.

Scager, K., Boonstra, J., Peeters, T., Vulperhorst, J., \& Wiegant, F. (2016). Collaborative learning in higher education: Evoking positive interdependence. $C B E-$ Life Sciences Education, 15(4), 1-9. doi: 10.1187/cbe.16-07-0219.

Skaniakos, T., \& Piirainen, A. (2019). The meaning of peer group mentoring in the university context. International Journal of Evidence Based Coaching and Mentoring, 17(1), 19-33. doi: 10.24384/EKNZ-S730.

Stanley, C. A., \& Porter, M. (Eds) (2002). Engaging large classes: Strategies and techniques for college faculty. Anker Publishing Company.

Stoeger, H., Hopp, M., \& Ziegler, A. (2017). Online mentoring as an extracurricular measure to encourage talented girls in STEM (Science, technology, engineering, and mathematics): An empirical study of one-on-one versus group mentoring. Gifted Child Quarterly, 61, 239-249. doi:10.1177/0016986217702215

Strayhorn, T. L., \& Terrell, M. C. (2007). Mentoring and satisfaction with college for black students. Negro Educational Review, 58(1-2), 69-83. 
Terrion, J. L. (2010). Motivation of peer mentors and unpaid peer helpers in higher education. International Journal of Evidence Based Coaching and Mentoring, 8(1), 85103.

Thompson, L. A., \& Kelly-Vance, L. (2001). The impact of mentoring on academic achievement of at-risk youth. Children and Youth Services Review, 23(3), 227-232.

Twigg, C. A. (2003). Improving quality and reducing cost: Designs for effective learning. Change: The Magazine of Higher Learning, 35(4), 22-29.

Won, M. R., \& Choi, Y. J. (2017). Undergraduate nursing student mentors' experiences of peer mentoring in Korea: A qualitative analysis. Nurse Education Today, 51, 8-14. doi:10.1016/j.nedt.2016.12.023.

Zarpelon, E., Resende, L.M., \& Reis, E.F. (2015). Is Mathematical background crucial to freshmen engineering students? Proceedings of 2015 International Conference on Collaborative Learning (ICL 2015), 1031-1035. 